\title{
Microstructure, Senescence and Texture Parameters of Sardo Cheese Applying Scanning Electron Microscopy With Image Analysis Techniques
}

Facundo Pieniazek ${ }^{1}$ and Valeria Messina ${ }^{* 1}$

1. The National Council for Scientific and Technical Research (CONICET), Rivadavia 1917, C1033AAJ, Argentina.

*Corresponding author: vmessina@citedef.gob.ar

\section{Abstract}

Sardo is a semi-hard and granular cheese made from cow's milk; commonly used for grating because it turns dryer and crumbly after ripening. The ripening stage is an essential process for the development of quality attributes [1]. The main problem of Sardo cheese is that ripening takes approximately 8-10 months and this represents a significant period of capital immobilization for the manufacture.

One of the most important quality parameters of cheese is their texture [2] [3]. Usually, texture parameters are evaluated by instrumental techniques but these are very expensive and destructive. Texture is also related to microstructure. It has been reported that changes during ripening are directly linked to structure [4]. To explain quality in cheese it is necessary to evaluate microstructure [4] [5].

The aim of the present research was to develop in first place a procedure using Scanning Electron Microscopy combined with image analysis technique to evaluate texture in Sardo cheese ripened at 4 and 8 months and in second place to evaluate different freeze drying cycles among ripening stages.

Micrographs revealed that when longer ripening stages were applied samples were more compact, darker, harder and higher amount of small pores appeared when compared to shorter ripening stages. On the other hand, when freeze drying process was applied cycles with lower temperatures and longer drying process, samples turned harder, darker and higher amount of pores appeared when compared to shorter stages. The size of the pore has influence in texture and rehydration ability; higher amount of pore with smaller sizes lead to a harder sample due to decreases in rehydration ability. In order to have optimal quality of Sardo cheese for grating and to reduce capital immobilization for the manufacture, ripening periods can be reduced from 8 to 4 months and shorter freeze drying cycles can be applied in order to maintain quality parameters. 


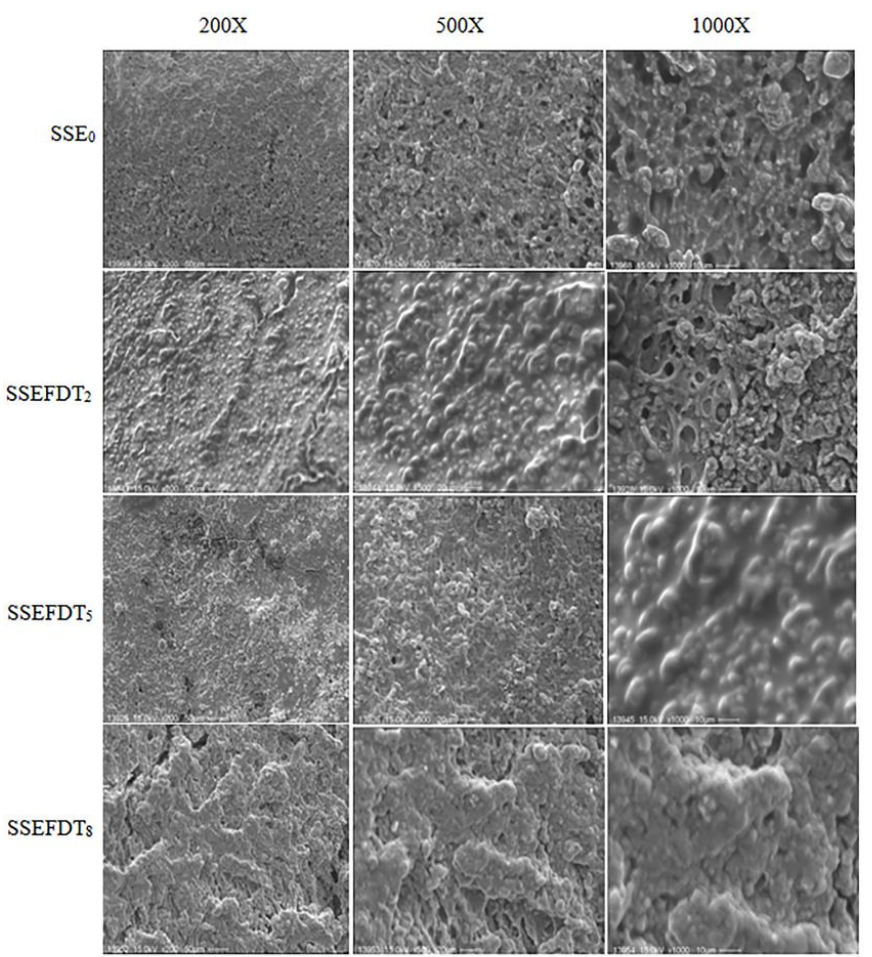

Figure 1 Scanning micrographs performed at 200, 500 and 1000 time's magnification of cross sectional Sardo cheese ripened at 4 months $\left(\mathrm{SSE}_{0}\right)$ and at different freeze drying (FD) cycles: $\mathrm{T}_{2}=$ $30^{\circ} \mathrm{C}(12 \mathrm{~h}) / 40^{\circ} \mathrm{C}(24 \mathrm{~h}) ; \mathrm{T}_{5}=-50^{\circ} \mathrm{C} \quad(12 \mathrm{~h}) / 40^{\circ} \mathrm{C}$ (24h); $\mathrm{T}_{8}=-70^{\circ} \mathrm{C}(12 \mathrm{~h}) / 40^{\circ} \mathrm{C}(24 \mathrm{~h})$.

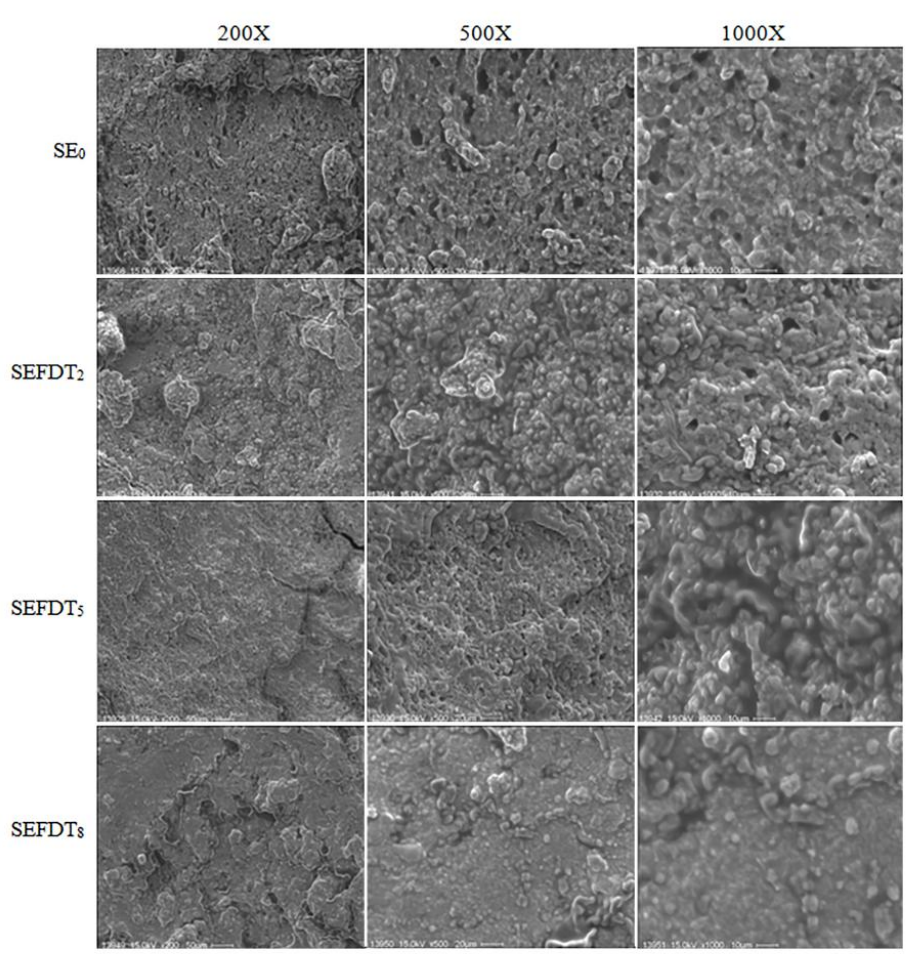

Figure 2 Scanning micrographs performed at 200, 500 and 1000 time's magnification of cross sectional Sardo cheese ripened at 8 months $\left(\mathrm{SE}_{0}\right)$ and at different freeze drying (FD) cycles: $-30^{\circ} \mathrm{C}(12 \mathrm{~h}) / 40^{\circ} \mathrm{C}(24 \mathrm{~h}) ; \mathrm{T}_{5}=-50^{\circ} \mathrm{C}$ $(12 \mathrm{~h}) / 40^{\circ} \mathrm{C}(24 \mathrm{~h}) ; \mathrm{T}_{8}=-70^{\circ} \mathrm{C}(12 \mathrm{~h}) / 40^{\circ} \mathrm{C}(24 \mathrm{~h})$.

\section{References}

[1] M Lerma-García, A Gori, L Cerretani, E Simó-Alfonso and M Caboni, Journal of Dairy Science, Vol. 93 No 10 (2010), pp. 4490-4496.

[2] R Kapoor and L Metzger, Comprehensive Reviews in Food Science and Food Safety, Vol. 7 (2008), pp. 194-214.

[3] P Fox, T Guinee, T Cogan and P McSweeney, Gaithersburg, MD, Aspen Publishers, Inc. (2000)

[4] C Hickey, M Auty, M Wilkinson and J Sheehan, Trends in Food Science and Technology, Vol. 41 No 2 (2015), pp. 135-148.

[5] M Černíková, R Salek, D Kozáčková, H Běhalová, L Luňáková and F Buňka, International Dairy Journal, Vol. 66 No 2 (2017), pp. 84-90. 